\title{
Pengaruh Penambahan Stophole Pada Bahan Komposit Epoxy Serat Kaca
}

\author{
The Effect of Adding a Stop Hole on Epoxy-Fibre Glass Composite \\ Heryanto B. Soemardi ${ }^{1}$, Kasijanto ${ }^{2}$, Sadar Wahjudi ${ }^{3}$, Kris Witono ${ }^{4}$, Nurlia P. Sari ${ }^{5}$ \\ 1,2,3,4 Teknik Mesin, Politeknik Negeri Malang, \\ Jl. Soekarno Hatta No.09 Malang Indonesia \\ 3sadar_wahjudi@yahoo.co.id \\ 5nurlia.pramita@gmail.com
}

\begin{abstract}
Abstrak--Telah banyak diteliti metode stophole untuk menghambat pertumbuhan retak pada bahan logam, namun belum ada penelitian tentang metode stophole ini untuk menghambat retak pada bahan komposit. Penelitian ini mengguankan komposit epoxy dan serat kaca dengan katalis epoxy hardener (polyaminoamide), arah serat yang digunakan adalah serat acak, lapisan komposit terdiri dari 4 lapis, dengan komposisi $30 \%$ serat, $69.7 \%$ resin, dan $0,3 \%$ katalis digunakan. Spesimen uji menggunakan CTS sesuai standar pengujian ASTM E 647 dengan retak awal sepanjang $20 \mathrm{~mm}$ dengan variasi diameter lubang stophole $2 \mathrm{~mm}, 3 \mathrm{~mm}, 4 \mathrm{~mm}$, dan $5 \mathrm{~mm}$ serta jarak lubang dan retak $5 \mathrm{~mm}, 10 \mathrm{~mm}$, dan $15 \mathrm{~mm}$. Hasilnya didapatkan jarak lubang yang paling optimum yang menyebabkan tegangan tarik tertinggi terletak pada jarak $10 \mathrm{~mm}$ dari ujung retak, dan diameter optimumnya adalah $5 \mathrm{~mm}$ dengan kekuatan tarik maksimum 22.74 Mpa, lebih tinggi daripada kekuatan tarik maksimum tanpa stophole (13.3 Mpa). Sehingga dapat disimpulkan adanya variasi stophole mempengaruhi tegangan tarik maksimum komposit epoxi serat gelas, karena pada ujung retak dan sisi lubang terdapat pemusatan tegangan, dan juga perbedaan mode patahan.
\end{abstract}

Kata Kunci- komposit, serat kaca, stophole, rambatan retak, kekuatan tarik.

Abstract - There have been many studies of stop hole methods to inhibit the growth of cracks in metallic materials, but still lacking in composite materials. This research used epoxy composite and glass fiber with epoxy hardener catalyst (polyaminoamide), the fiber direction used was random fiber, composite layers consist of 4 layers, with $30 \%$ fiber composition, $69.7 \%$ resin, and $0.3 \%$ catalyst were used. The test specimens use CTS as per ASTM E 647 testing standard which has a $20 \mathrm{~mm}$ initial fracture with $2 \mathrm{~mm}, 3 \mathrm{~mm}, 4 \mathrm{~mm}$, and $5 \mathrm{~mm}$ stophole diameter variations and $5 \mathrm{~mm}, 10 \mathrm{~mm}$, and $15 \mathrm{~mm}$ hole and crack spacing. Result shows the most optimum stophole distance that causes the highest tensile stress at $10 \mathrm{~mm}$ distance, and $5 \mathrm{~mm}$ diameter (22.74 Mpa). This value higher than the maximum tensile strength without stophole (13.3 MPa). It can be concluded that the variation of stophole affects the maximum tensile stress of glass fiber epoxi composites, caused by the crack tip and the side of the hole there is tension concentration, and different fracture mode.

Key Words - composite, fiber glass, stop hole, crack growth, tensile strength.

\section{Pendahuluan}

Kegagalan pada suatu struktur dapat terjadi dalam berbagai wujud seperti yielding, retak, patah, scoring, pitting, korosi, aus, dan lain-lain. Faktor penyebab kegagalan juga bermacam- macam seperti misalnya salah desain, beban operasional, kesalahan maintenance, cacat material, temperatur, lingkungan dan waktu. Dengan pengetahuan yang lengkap tentang kegagalan, maka para pakar akademisi dapat mempertimbangkan berbagai aspek penyebab kegagalan dalam perancangan sehingga diharapkan kegagalan tidak akan terjadi selama umur teknisnya. Retak merupakan suatu fenomena pada material yang terjadi akibat beban yang diberikan. Retak merupakan awal mula dari terjadinya kegagalan pada material.

Berbagai metode untuk menghambat perambatan retak (crack retardation) telah banyak dikembangkan. Salah satunya adalah membuat lubang di sekitar ujung retak (metode stophole). Telah dikembangkan prosedur stop drilling untuk meningkatkan umur fatik pada material 6061-T651 aluminium alloy dan AISI 304 stainless steel. Hasil penelitiannya menunjukkan dengan memperbesar diameter stop hole (lubang penghambat retak), cenderung meningkatkan umur fatik. Pada diameter 2, 2.5, and $3 \mathrm{~mm}$ menghasilkan peningkatan total umur fatik pada spesimen 6061-T651 sebesar masing-masing $187 \%$, 321\%, dan 443\%, sedangkan pada material AISI 304 sebesar masing-masing 72\%, 121\%, dan 174\%[1]. Juga dilakukan hal yang sama dengan 6 buah stophole. Hasilnya terjadi peningkatan nilai $\mathrm{K}$ pada awal siklus. Tetapi seiring dengan pertambahan siklus, rambatan retakan semakin cepat jika dibandingkan dengan yang tidak diberi stophole[2]. Penelitian lainnya tentang evaluasi faktor intensitas tegangan pada ujung retak dengan lubang penghambat rambat retak disimpulkan bahwa konfigurasi lubang dengan variasi diameter, jarak lubang terhadap ujung retak dan jarak antar lubang masing-masing mempengaruhi nilai KI [3].

Parameter faktor intensitas tegangan (stress intensity factor), KI, sangatlah penting untuk diketahui, karena melalui parameter ini akan dapat diketahui cepat atau tidaknya perambatan suatu konfigurasi retak pada suatu komponen. Semakin besar harga KI, maka retak tersebut akan mudah merambat [4]. Parameter faktor intensitas tegangan akan menentukan besarnya distribusi tegangan di ujung retak. Interaksi tegangan antara tegangan di ujung retak dan tegangan di sekitar lubang memberikan pengaruh pada $\mathrm{K}$ di ujung retak sebagai parameter perambatan retak selanjutnya.

Sebagai bahan teknik, komposit dinilai lebih unggul daripada bahan logam dikarenakan memiliki bobot lebih 
ringan, memiliki kekuatan dan kekakuan yang baik, juga tahan terhadap korosi. Komposit merupakan penggabungan antara dua atau lebih komponen/bahan, sehingga sifatnya dipengaruhi oleh bahan pengikat dan bahan pengisinya.

Sampai saat ini masih pemahaman tentang bahan komposit terbatas karena sifatnya yang merupakan penggabungan oleh bahan penyusunnya yang bermacammacam, arah serat, serta jumlah lapisannya. Lapisan 4 serat matriks epoxy serat kaca dinilai memiliki kekuatan tarik lebih tinggi daripada beberapa lapisan lainnya (56.42 MPa)[5]. Patahan yang dihasilkan pada pengujian tarik adalah patah getas sehingga interaksi tegangan antara tegangan di ujung retak dan tegangan di sekitar lubang pada komposit perlu diperhatikan dikarenakan distribusi kekuatan pada komposit dipengaruhi oleh serat atau bahan pengisi komposit. Oleh karena itu metode stop hole sebagai salah satu penghambat retak pada komposit sangat perlu untuk diteliti.

\section{METODE PENELITIAN}

Pada penelitian ini digunakan epoxy sebagai pengikat serat dan serat kaca sebagai penguat dengan arah serat anyam, dan katalis epoxy hardener (polyaminoamide). Lapisan komposit terdiri dari 4 lapis, dengan komposisi 30\% serat, 69.7\% resin, dan $0,3 \%$ katalis. Spesimen uji yang digunakan adalah CTS sesuai standar pengujian ASTM E 647 dengan retak awal sepanjang $20 \mathrm{~mm}$. Metode yang digunakan untuk pembuatan komposit adalah metode hand lay-up.

Diameter stophole yang digunakan adalah diameter 2,3,4, dan $5 \mathrm{~mm}$ dengan jarak antara ujung retak dengan lubang adalah 5, 10, dan $15 \mathrm{~mm}$.

Spesimen komposit yang telah dibuat dengan metode hand lay-up kemudian dicari kekuatan tarik bengkok maksimumnya menggunakan mesin uji tarik universal Dengan kecepatan penarikan sebesar $0,2 \mathrm{~mm} / \mathrm{s}$.

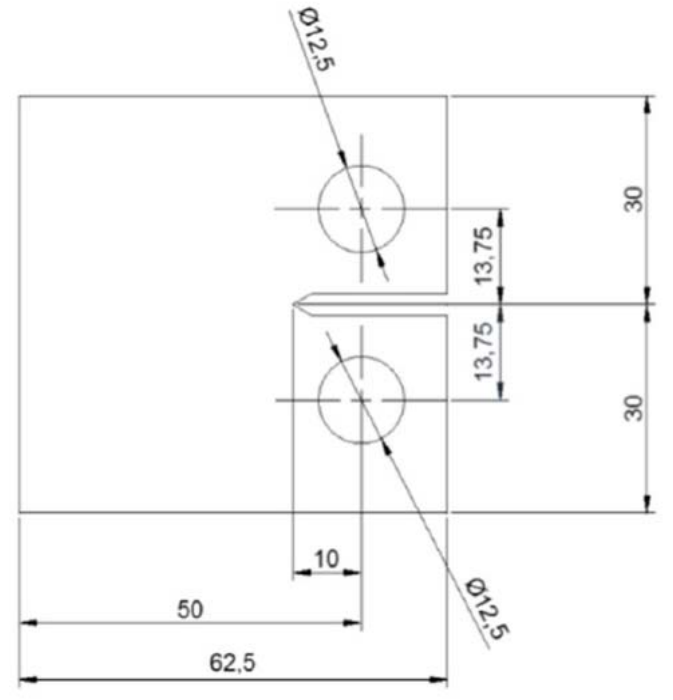

Gbr 1. Spesimen uji

Komposit serat gelas yang telah dibuat, dibentuk sesuai standar dimensi spesimen CTS ASTM E 647.

\section{HASIL DAN PEMBAHASAN}

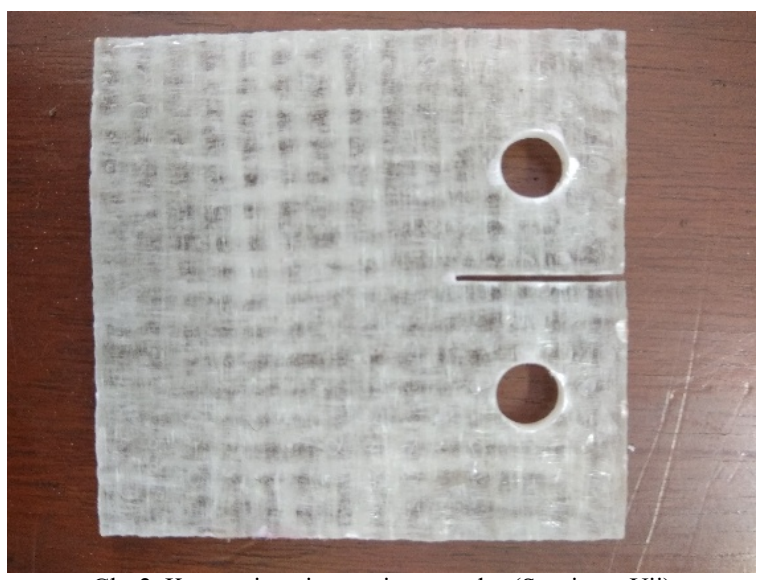

Gbr 2. Komposit resin epoxi serat gelas (Spesimen Uji)

Dapat dilihat pada gambar 5.2 dimensi specimen uji tarik memiliki panjang $62.5 \mathrm{~mm}$ dan tebal $3 \mathrm{~mm}$ dan celah sepanjang $20 \mathrm{~mm}$. Untuk menghitung tegangan tarik maximum perlu diketahui berapa luas penampang (A) area tarik specimen $127.5 \mathrm{~mm} 2$.

Dari pengujian uji tarik didapatkan data load $(\mathrm{kg})$, dan dari luas penampang didapatkan besarnya tegangan tarik maksimum.

\section{Kekuatan Tarik Maksimum}

TABEL 1

KEKUATAN TARIK SPESIMEN TERHADAP JARAK LUBANG DAN DIAMETER LUBANG STOP HOLE

\begin{tabular}{|c|c|c|c|c|}
\hline $\begin{array}{c}\text { Jarak } \\
\text { Lubang } \\
\text { dengan } \\
\text { retak }(\mathbf{m m})\end{array}$ & $\begin{array}{c}\text { Diameter } \\
\text { Lubang } \\
(\mathrm{mm})\end{array}$ & $\begin{array}{c}F \\
(\mathbf{k g})\end{array}$ & $\mathbf{F}(\mathbf{N})$ & $\begin{array}{c}\text { Kekuatan } \\
\text { Tarik } \\
\text { (Mpa) }\end{array}$ \\
\hline \multicolumn{2}{|c|}{ Retak Tanpa Stop Hole } & 174 & 1705.2 & 13.36887 \\
\hline \multirow{4}{*}{5} & 2 & 162 & 1587.6 & 12.44688 \\
\hline & 3 & 230 & 2254 & 17.6715 \\
\hline & 4 & 170 & 1666 & 13.06154 \\
\hline & 5 & 174 & 1705.2 & 13.36887 \\
\hline \multirow{4}{*}{10} & 2 & 216 & 2116.8 & 16.59584 \\
\hline & 3 & 295 & 2891 & 22.66562 \\
\hline & 4 & 235 & 2303 & 18.05566 \\
\hline & 5 & 296 & 2900.8 & 22.74245 \\
\hline \multirow{4}{*}{15} & 2 & 120 & 1176 & 9.219914 \\
\hline & 3 & 126 & 1234.8 & 9.680909 \\
\hline & 4 & 134 & 1313.2 & 10.29557 \\
\hline & 5 & 180 & 1764 & 13.82987 \\
\hline
\end{tabular}

Sumber: analisa laboratorium

Dari tabel diatas dapat digambarkan grafik pengaruh diameter dan jarak lubang stophole dengan tegangan maksimum bahan yang didapat dari hasil pengujian tarik. 


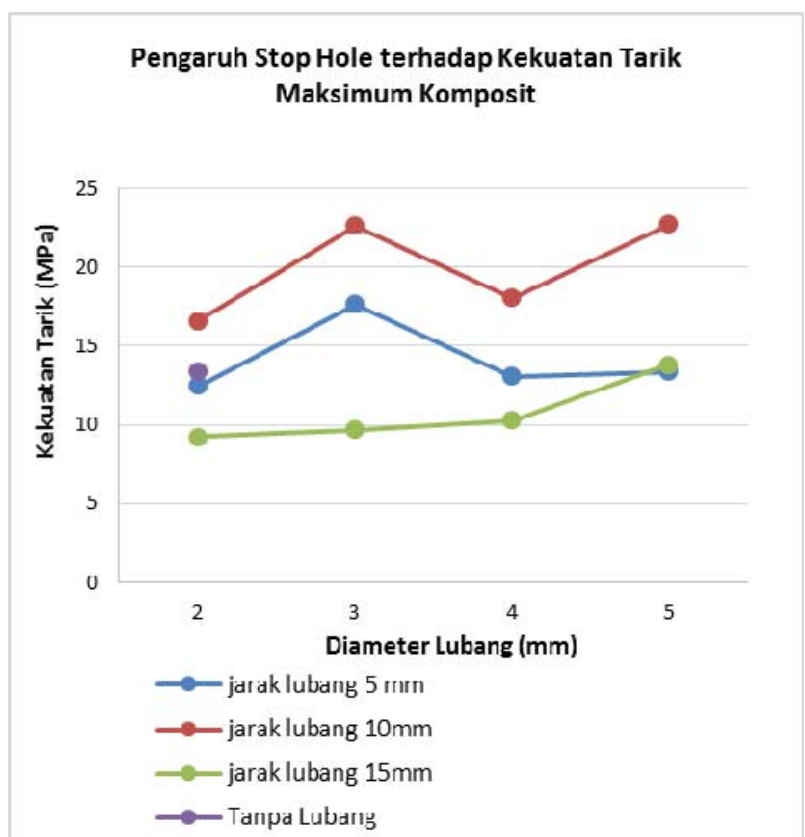

Gbr 3. Grafik Pengaruh Stophole terhadap kekuatan tarik maksimum komposit.

Pada gambar 3 dijabarkan tentang pengaruh adanya stophole terhadap kekuatan tarik maksimum komposit epoxi serat gelas. Hasilnya menunjukkan bahwa jarak lubang maupun diameter lubang stop hole mempengaruhi kekuatan tarik maksimum dari komposit epoxi serat gelas. Kekuatan tarik maksimum terletak pada jarak lubang stophole $10 \mathrm{~mm}$, kemudian $5 \mathrm{~mm}$, dan paling rendah ada pada jarak lubang $5 \mathrm{~mm}$. Jarak lubang stophole $10 \mathrm{~mm}$ merupakan jarak lubang optimum terhadap kekuatan tarik komposit epoxi serat gelas. Pada ujung retak dan sisi lubang terdapat pemusatan tegangan. Secara umum, adanya lubang di sekitar ujung retak akan mengakibatkan interaksi tegangan yang melibatkan tegangan di ujung retak dan sisi lubang tersebut. Pada jarak yang terlalu dekat, pemusatan tegangan bercampur antara ujung retak dan sisi lubang sehingga menyebabkan kekuatan tariknya rendah. Sedangkan apabila jarak lubang terlalu jauh, interaksi antara tegangan di ujung retak dan lubang berkurang sehingga adanya lubang tidak mempengaruhi kekuatan tarik maksimum spesimen.

Dari diameter $2 \mathrm{~mm}$ ke $3 \mathrm{~mm}$ terjadi kenaikan yang signifikan pada tegangan maksimum, kemudian penurunan saat $4 \mathrm{~mm}$ dan naik kembali pada diameter $5 \mathrm{~mm}$. Tegangan maksimum dipengaruhi oleh faktor geometri dari spesimen. Penambahan lubang stophole yang berbeda diameter akan menyebabkan geometri spesimen berubah, sehingga mempengaruhi pemusatan tegangan pada spesimen. Semakin kecil dimeter stophole akan terdapat pemusatan tegangan sisi lubang yang semakin besar, sedangkan semakin besar diameter stophole akan mengurangi pemusatan tegangan sisi lubang.
Perilaku perambatan retak a. Tanpa Stophole

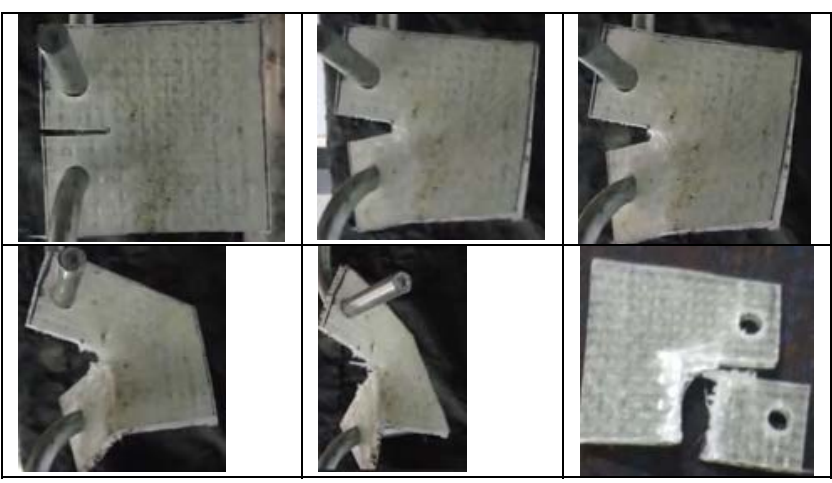

Gbr 4. Foto Perambatan Retak pada spesimen tanpa stophole

Gambar 4 menunjukkan urutan foto perambatan retak yang diambil dari rekaman video pada spesimen untuk pembebanan mode I tanpa stophole. Kondisi awal sebelum inisiasi retakan kemudian perambatan retakan hingga spesimen patah Arah retakan seperti ditunjukkan dalam Gambar terlihat bahwa terjadi perbedaan sudut (tidak searah) dengan ujung retakan awal pada permukaan spesimen karena deformasi bibir geseran (shear-lip). Ini terus berlanjut hingga akhir, sehingga terlihat seperti robekan. Dari hasil ini, dapat diketahui bahwa mekanisme utama dari perambatan retak adalah terjadi retakan jenis bukaan(KI) kemudian diikuti dengan retakan jenis sobekan (KIII).

\section{b. Dengan Stophole}

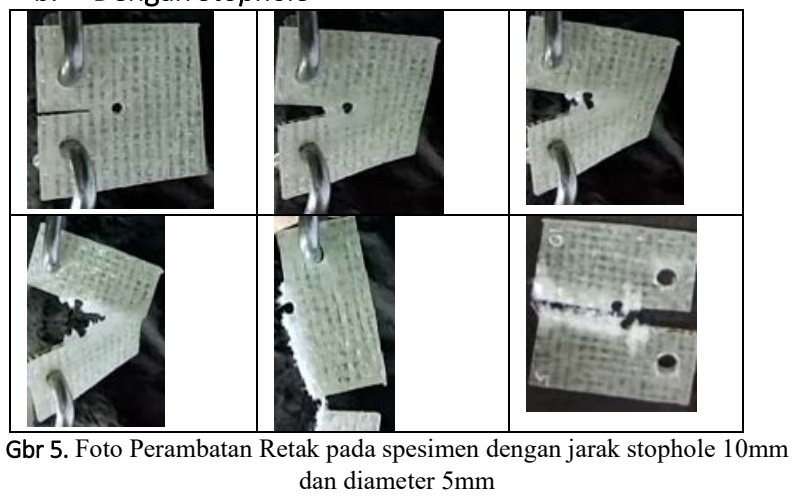

Gambar 5 menunjukkan urutan foto perambatan retak yang diambil dari rekaman video pada spesimen dengan jarak stophole $10 \mathrm{~mm}$ dan diameter $5 \mathrm{~mm}$. Mulai dari kondisi awal sebelum inisiasi retakan hingga spesimen patah. Arah retakan seperti ditunjukkan dalam Gambar 5 terlihat bahwa perambatan retakan sejajar terhadap retakan awal dan retakan rata (flat fracture) hingga akhir spesimen. Dari hasil ini, dapat diketahui bahwa mekanisme utama dari perambatan retak adalah terjadi retakan jenis bukaan(KI). 


\section{KESIMPULAN}

Adanya variasi stophole mempengaruhi tegangan tarik maksimum komposit epoxi serat gelas, karena pada ujung retak dan sisi lubang terdapat pemusatan tegangan. Adanya lubang di sekitar ujung retak akan mengakibatkan interaksi tegangan yang melibatkan tegangan di ujung retak dan sisi lubang tersebut. Tegangan maksimum dipengaruhi oleh faktor geometri dari spesimen. Penambahan lubang stophole yang berbeda diameter akan menyebabkan geometri spesimen berubah, sehingga mempengaruhi pemusatan tegangan pada spesimen.

Pada spesimen tanpa stophole, rambatan retak yang terjadi adalah jenis bukaan (KI) kemudian diikuti dengan jenis robekan (KIII). Sedangkan mekanisme utama dari perambatan retak spesimen dengan stophole adalah terjadi retakan jenis bukaan(KI). Penambahan stophole dapat mempengaruhi alur perambatan retak.

\section{UCAPAN TERIMA KASIH}

Terima kasih disampaikan kepada Politeknik Negeri Malang yang telah memberikan dana penelitian ini.

\section{REFERENSI}

[1] P.S. Song, Y.L. Shieh, 2004,"Stop drilling procedure for fatigue life improvement", International Journal of Fatigue, Vol. 26, 1333-1339.

[2] Fani A., 2013, "Perilaku Striation pada penampang patahan plat alluminium disekitar daerah Stop Drilled Hole", Skripsi Teknik Mesin, Universitas Brawijaya, Malang

[3] Punowidodo, Anindito, 2010. "Evaluasi Faktor Intensitas Tegangan pada Ujung Retak dengan Lubang Penghambat Rambat Retak", Jurnal Rekayasa Mesin Vol. 1 No. 1.

[4] Tada, H. Paris,P. Irwin,G..1985. "The Stress Analysis of Cracks Handbook". Paris Production, Inc. St. Louis

[5] Nugroho, Yosep D., 2016, "Karakteristik Komposit Serat Gelas dengan Variasi Jumalh Lapisan Serat", Skripsi Teknik Mesin, Universitas Sanata Dharma, Yogyakarta 